\title{
La acción declarativa de inconstitucionalidad en la Provincia de Buenos Aires*
}

Arodín Valcarce

\section{Control de constitucionalidad en el ámbito provincial}

El sistema de control de constitucionalidad en las provincias, parte de una distinción elemental. Los tribunales locales tienen que controlar dos clases de leyes, las que emanan del Congreso Nacional, según el Art. $75^{\circ}$ inciso 12) $\mathrm{CN}$, esto es las de derecho común y las que producen las legislaturas locales. Esta tarea se debe realizar con arreglo a sistemas diferentes: el control de las leyes nacionales sigue las pautas establecidas en el orden federal por la Corte Suprema de Justicia de la Nación, en tanto el control de derecho local se realiza: a) por medio del sistema difuso, y b) a través de las llamadas acciones declarativas de inconstitucionalidad, que están concentradas en la competencia originaria de las cortes supremas locales, especialmente pensado para las normas locales. ${ }^{1}$

Nuestro más alto Tribunal ha señalado que «contra las leyes y decretos provinciales que se califican de ilegítimos, caben tres procedimientos y jurisdicciones según la calidad del vicio imputado: a) si son violatorios de la Constitución Nacional, tratados con las naciones extranjeras, o leyes federales, debe irse directamente a la justicia nacional; si se arguye que una ley es contraria a la constitución provincial, y c) si se sostiene que la ley, el decreto, etc., son violatorios de las insti-

* Documento presentado al XXI Congreso Nacional de Derecho Procesal, llevado a cabo entre el 13 y el 16 de junio de 2001 en San Juan, Argentina.

1 Alberto Bianchi.- "El control abstracto de constitucionalidad según el Tribunal Superior de Justicia de la ciudad de Buenos Aires", ED 19-10-2000, p. 6. 
tuciones provinciales y nacionales debe irse primeramente ante los estrados de la justicia provincial y en su caso, llegar a esta Corte por el recurso extraordinario del Art. $14^{\circ}$ de la Ley No $48{ }^{2}{ }^{2}$

\subsection{Vías de control de constitucionalidad en la provincia de Buenos Aires}

La Suprema Corte de Justicia de la Provincia de Buenos Aires sostiene que "a la luz de las pautas jurisprudenciales y en el marco de las normas constitucionales y legales aplicables en el ámbito local, los justiciables tienen diversas vías para llevar a conocimiento de un juez una cuestión de naturaleza constitucional. Ellas son la «acción de inconstitucionalidad», propia de las atribuciones originarias y exclusivas de la Suprema Corte de Justicia y las "defensas de inconstitucionalidad", autorizada por el Art. $31^{\circ}$ de la Constitución Nacional. Esto sin obviar la facultad que el constituyente de 1994, atribuye al juez del amparo de declarar la inconstitucionalidad de la norma en que se funda el acto u omisión lesivos (Art. $20^{\circ}$, inciso 2) de la Constitución Provincial del voto de la mayorías. ${ }^{3}$

La Constitución de la Provincia de Buenos Aires consagra enfáticamente la supremacía de sus disposiciones estableciendo que toda ley, decreto $u$ orden contrarios a las declaraciones, derechos y garantías estatuidos en los arts. $1^{\circ}$ al $56^{\circ}$ (anteriores $1^{\circ}$ a $43^{\circ}$ ), o que impongan otras restricciones que las que tales normas permiten, o priven a los ciudadanos de las garantías que aseguren, serán inconstitucionales y no podrán ser aplicados por los jueces (Art. 570, anterior 440). ${ }^{4}$

Ahora bien, sentadas tales premisas introductorias, destacamos que en el ordenamiento provincial bonaerense, el control de constitucionalidad de las normas jurídicas se canaliza a través de las siguientes vías: a) Acción declarativa de inconstitucionalidad (Art. 161\%, inc. 1 CPBA y arts. $683^{\circ}$ a $688^{\circ} \mathrm{CPCC}$ ); b) El recurso extraordinario de

2 CSJN, Fallos 176, 176:315; 311:1588; íd. 30-5-95, LL, 1996-A-558, citado por Alí Joaquín Salgado y Alejandro César Verdaguer, Juicio de amparo y acción de inconstitucionalidad. Ed. Astrea, 2da. Edición, 2000, p. 383.

3 SCBA, marzo 3 de 1998, "Cebitronic SA c. Provincia de Buenos Aires», Carpetas DP, 1780 .

4 Roberto Omar Berizonce, "Recursos judiciales", coordinador Osvaldo Alfredo Gozaíni, Ed. Ediar, año 1993, pp. 200-201. 
inconstitucionalidad (Art. $161^{\circ}$, inc. $1^{\circ} \mathrm{CPBA}$ y arts. $299^{\circ}$ a $303^{\circ} \mathrm{CPCC}$ ); c) El recurso extraordinario de nulidad (Art. $161^{\circ}$ inc. 3 CPBA y arts. $296^{\circ}$ a $298^{\circ}$ CPCC); y, d) Las Garantías Constitucionales de Hábeas Corpus, Amparo y Hábeas Data (Art. 20 CPBA).

\section{La acción de inconstitucionalidad en la Provincia de Buenos Aires}

\subsection{Normativa vigente. Antecedentes.}

El ejercicio de la jurisdicción originaria para conocer la constitucionalidad o inconstitucionalidad de las leyes, decretos, ordenanzas o reglamentos está consagrado en el Art. $161^{\circ}$ inc. 1) de la Constitución provincial y regulado en los arts. $683^{\circ}$ a $688^{\circ}$ del CPCC.

El Art. $161^{\circ}$ de la CPBA establece «la Suprema Corte de Justicia tiene las siguientes atribuciones: $1^{\circ}$ (Constitucionalidad de las normas) - Ejerce jurisdicción originaria y de apelación para conocer y resolver acerca de la constitucionalidad o inconstitucionalidad de leyes, decretos, ordenanzas o reglamentos que estatuyan sobre materia regida por esta Constitución y se controvierta por parte interesada». Dicho artículo fue consagrado por primera vez por la Convención Constituyente de 1873 (Art. $136^{\circ}$ inc. 1) y ha permanecido inalterable hasta la actualidad, con la sola modificación producida en la reforma del año 1889 que incluyó a la ordenanza (Art. $157^{\circ}$ inc. 1) Constitución Provincial 1889; Art. $149^{\circ}$, inc. 1, Constitución Provincial 1934). ${ }^{6}$

La demanda de inconstitucionalidad ya estaba incluida en el Código de Procedimientos Civiles de 1880, se mantuvo en el Anteproyecto de 1961, el que fue ajustado por la Comisión revisora de 1966 y se incorporó sin enmiendas al Proyecto de la Subsecretaría de justicia de la provincia, en octubre de $1967^{7}$. Actualmente la acción declarativa

5 Ana Cristina Logar, «El control de constitucionalidad en el Código contencioso administrativo de la Provincia de Buenos Aires (su deslinde con otras vías de control de constitucionalidad en el ámbito local)". ED 26-4-2000, pp. 4-5.

6 Ana Cristina Logar, op. cit. p. 16, nota 11.

7 Morello, Passi Lanza, Sosa, Berizonce, Códigos procesales en lo civil y comercial de la Provincia de Buenos Aires y de la Nación. Ed. Librería editora PlatenseAbeledo Perrot, año 1976, t. VII, p. 925. 
de inconstitucionalidad está regulada en los arts. $683^{\circ}$ a $688^{\circ}$ del CPCC, siendo su finalidad primordial asegurar la supremacía de la Constitución provincial. $^{8}$

\subsection{Objeto del juicio}

El Art. $683^{\circ}$ del Código Procesal Civil y Comercial de la Provincia de Buenos Aires establece que «de acuerdo a lo dispuesto por la Constitución de la Provincia se podrá demandar la declaración de inconstitucionalidad de ley, decreto, ordenanza o reglamento que estatuya sobre materia regida por aquella, debiendo observarse el siguiente procedimiento".

La Suprema Corte de la Provincia de Buenos Aires conoce la constitucionalidad o inconstitucionalidad de las leyes, decretos, ordenanzas o reglamentos, originariamente, por demanda, o en revisión, a través del recurso extraordinario de inconstitucionalidad -Art. $161^{\circ}$ CPBA-. ${ }^{9}$ La primera vía (acción de inconstitucionalidad), regulada a partir del artículo citado ut supra, cumple una función eminentemente preventiva, bastando un interés legítimo, sin necesidad de un derecho transgredido; es decir, se anticipa a la aplicación del precepto reputado inconstitucional ${ }^{10}$, siendo suficiente que la ley, decreto $u$ ordenanza se haya promulgado. ${ }^{11}$

Si bien la acción de inconstitucionalidad no es procedente una vez que el daño concreto emergente del precepto inconstitucional se hubiere producido, debido a que el efecto presuntamente declarativo de la sentencia a pronunciar sería absolutamente ineficaz para remediar un perjuicio consumado, esta regla no se aplica a aquellos casos en que el perjuicio concreto no se ha consumado íntegramente. ${ }^{12}$

Sin desconocer el carácter preventivo de la acción de inconstitucionalidad, es posible extender sus alcances más allá de la mera declaración $^{13}$. El objeto prístino de la acción de inconstitucionalidad es el preven-

8 SCBA 16-7-68, ED 24-910.

9 SCBA, Ac. y sentencia 1968, p. 521;1973-Il-1141.

10 SCBA, Ac. y sentencia 1967-I-361; 10-4-84, DIBA, 126-265; 27-4-82-D-113.

11 SCBA, B-55.366, 14-IX-93.

12 Alí Joaquín Salgado y Alejandro César Verdaguer, op. cit., p. 430; SCBA, 9-12-81.

13 Alí Joaquín Salgado y Alejandro César Verdaguer, "Juicio de amparo y acción de inconstitucionalidad» Ed. Astrea, año 2000, p. 427. 
tivo, ya que por su intermedio se obtiene el socorro de los derechos y garantías que la ley fundamental de la Provincia consagra, sin esperar a que ocurra la aplicación del precepto o de la decisión inconstitucional y en tanto pueda seguirse de ella un menoscabo de los derechos del demandante. Pero si la lesión ya se ha generado puede la Corte disponer la consecuencia anulatoria, para satisfacer el derecho conculcado, pues no es la circunstancia de que el daño se haya consumado lo que obsta al progreso de la acción, sino el vencimiento del término legal para interponer la demanda, que comienza a correr desde el momento de la efectiva aplicación de la ley impugnada. Que la acción de inconstitucionalidad sea preventiva no quiere decir que ese resulte su objeto exclusivo, también puede ser anulatoria si se cuestiona paralelamente a la norma general: la «aplicación» que se hizo de ella, cuando -obviamente- el perjuicio ya se ha producido ${ }^{14}$.

\subsubsection{Causa de la pretensión}

Sólo procede por infracciones a la Constitución de la Provincia, y no por lesión a la Constitución Nacional, ${ }^{15}$ en la medida que la norma reputada inconstitucional se encuentre vigente o subsistan sus efectos. ${ }^{16}$ Sin embargo, este principio no impide la valoración de las cuestiones federales indispensables para razonar lógicamente sobre la alegada infracción a los límites resultantes del Art. $1^{\circ}$ in fine de la Constitución de la Provincia de Buenos Aires, o la invocación de normas de igual naturaleza, como argumentos coadyuvantes de principios de derecho constitucional local. Ello mientras los fundamentos de la demanda coincidan con la pretendida violación de normas de la Constitución provincial. ${ }^{17}$

Berizonce señala que un notable vacío se deriva de la interpretación restrictiva que ha impuesto que la acción de inconstitucionalidad deba circunscribirse, exclusivamente a materias regidas por la constitución local, considerando ajena, e insusceptible de ser tratada, la violación de disposiciones de la Constitución Nacional. Para dicho autor

14 SCBA; I. 1896, "Marino, María B. Y otra s/Inconstitucionalidad Art. 10ª de la Ley 11,685" DJJ II, 14 y 15-8-2000 (voto del Dr. Hitters).

15 SCBA, I1 169, 11-XII-84.

16 SCBA, I 1350, 23-XI-93.

17 Alí Joaquín Saldadoy Alejandro César Verdaguer, op. cit., p. 435. 
-siguiendo a Ibáñez Frocham- la distinción entre el contenido de la «cuestión constitucional local" y el "caso federal" casi siempre resulta artificiosa e insustancial, pues la impugnación se concreta en un mismo argumento y en una misma pretensión, no siendo siquiera el caso de acumulación objetiva de pretensiones. El paralelo de los derechos y garantías, según están previstos en una y otra Constitución, es casi absoluto, de modo que sólo una interpretación disfuncional puede escindir las impugnaciones cuando tienen un único sustento (v. gr., la garantía de la propiedad, o de la defensa en juicio, o la de trabajar y ejercer industria lícita, etc.). Queda sin razón, entonces aquella doctrina legal restrictiva. ${ }^{18}$

Únicamente son impugnables las normas que, con independencia de su denominación, constituyen mandatos generales, abstractos e impersonales dirigidos a la comunidad ${ }^{19}$, y no los actos de alcance individual ${ }^{20}$; así, las sentencias no pueden ser declaradas inconstitucionales ${ }^{21}$, tampoco son impugnables por esta vía, las resoluciones administrativas que deciden casos particulares por aplicación, correcta o equivocada, de normas superiores ${ }^{22}$, ni procede esta acción por violación de normas legales, que sólo provocan transgresión constitucional en forma refleja ${ }^{23}$, esto es, cuando sólo media quebrantamiento de la norma inferior, de las disposiciones legales a la que está subordinada. ${ }^{24}$

De este modo se persigue, por vía de acción, asegurar la supremacía de la Constitución Provincial. Se trata de una impugnación optativa, cuyo no uso dista de agotar el derecho de fondo, en este caso igualmente expedito para hacerlo valer por las vías ordinarias del enjuiciamiento tradicional reservado para cuando, por la aplicación práctica de la ley inconstitucional, el daño ya ha sucedido. ${ }^{25}$

18 Roberto Omar Berizonce, op. cit., p. 203.

19 SCBA, I 1612, 8-VI-93.

20 SCBA, B 52.137, 21-XII-93.

21 SCBA, 8-11-83, ac. 32.208.

22 SCBA, Ac. y sent. 1972-III-453.

23 SCBA, Ac. y sent. 1963-II-932.

24 Morillo-Sosa-Berizonce-Tessone, Código de procedimientos civil y comercial de la Provincia de Buenos Aires y de la Nación. Ed. Abeledo Perrot, año 1996, p. 577. SCBA, I 1329, 10-XII-92.

25 SCBA, Ac. y Sent., 1967, v. I, p. 361. 


\subsubsection{Legitimación}

Para promover la demanda de inconstitucionalidad es necesario acreditar la calidad de parte interesada, vale decir que el ejercicio del derecho por quien la deduce se halla afectado en razón de la aplicación de la ley, decreto, ordenanza o reglamento cuya constitucionalidad se controvierte. ${ }^{26}$

El interés legítimo depende de la concurrencia de actos inequívocos que revelen que el precepto impugnado ha sido o será indudablemente aplicado al actor ${ }^{27}$, habiéndose acotado que importa una decisión abstracta el pronunciamiento que se recaba cuando la parte actora carece de dicho interés. ${ }^{28}$

La acción de inconstitucionalidad es procedente cuando está motivada en un interés jurídico concreto y no en causas genéricas y abstractas que son incompatibles con la competencia de la Corte ${ }^{29}$, de ello se sigue que si el actor obtuvo la satisfacción de su pretensión jurídica en un trámite que dedujo simultáneamente con la acción de inconstitucionalidad, no procede decidir el caso puesto que ello importaría dictar una sentencia abstracta ${ }^{30}$, tampoco procede juzgar la validez constitucional de normas que han dejado de regir al tiempo de la sentencia ${ }^{31}$, salvo cuando el actor conserva un interés concreto motivo de la subsistencia de efectos definitivamente producidos por aquellas ${ }^{32}$, así ocurre cuando la demanda fue promovida durante la vigencias de la norma y el actor procura la devolución de haberes retenidos en aquel tiempo ${ }^{33}$, el interés debe subsistir en el momento del pronunciamiento definitivo. ${ }^{34}$

El anteproyecto de CPCC para la Provincia de Buenos Aires, elaborado por los doctores Eisner, Arazi, Kaminker y Morello, en su Art. $683^{\circ}$ in fine, establece que "parte interesada", cuando se cuestionen preceptos de carácter institucional, será toda persona que demuestre que resulta afectada como integrante de la comunidad.

26 SCBA, Ac. y Sent., 1959, v. III, p. 222.

27 SCBA, I 1465, I-VI-93.

28 SCBA, Ac. y sent., 1961, v. V, p. 264.

29 SCBA, Ac. y sent., 1971, v. II, p. 674.

30 SCBA, Ac. y sent., 1963, v. II, p. 937.

31 SCBA, Ac. y sent., 1969, v. 345, 1971, v. II, p. 204.

32 SCBA, Ac. y sent., 1962, v. III, p. 1061.

33 SCBA 10-3-81, I 1072., "doctrina de fallos", marzo 1980. 
Frente al cuestionamiento que se formuló a la legitimación activa de la Municipalidad de La Plata (que había planteado la inconstitucionalidad de un decreto por considerarlo violatorio del régimen municipal), la Suprema Corte de Justicia, señaló que el municipio estaba legitimado para efectuar dicho planteo, en razón de que el intendente tiene la atribución y el deber de representar y hacerse representar en juicio en defensa de los intereses comunales. $^{35}$

En materia de derechos de incidencia colectiva, la Suprema Corte consideró legitimada a una ciudadana que planteó la inconstitucionalidad de la Ley No 11,366 de la Provincia de Buenos Aires que concede a la Corporación de Defensa Costera las tierras que ganase al río, a cambio de la construcción de obras de defensa costera. ${ }^{36}$

\subsubsection{Acumulación de pretensiones}

Como quedó dicho, la demanda originaria de inconstitucionalidad tiene una finalidad eminentemente preventiva. Así, como regla general, se ha resuelto, que no es dable acumular la pretensión de inconstitucionalidad y la de repetición de impuestos; sin perjuicio de que la infracción constitucional sirva de argumento fundante de la falta de causa en el pago del tributo. ${ }^{37}$

En principio la Suprema Corte no admite que a la acción de inconstitucionalidad se le pueda acumular una pretensión de condena. Excepcionalmente se ha resuelto que es admisible la acumulación de la acción de condena a la de inconstitucionalidad, por cuanto el reclamo de condena no es sino una consecuencia necesaria e inescindible, en el caso, de la declaración de inconstitucionalidad y representa el interés jurídico y patrimonial del peticionante que persigue el reconocimiento del perjuicio ocasionado. Resulta así que se acumulan una acción principal y otra secundaria, siendo la primera el presupuesto necesario para la segunda ${ }^{38} \mathrm{La}$ demanda de condena, que se acumula a la acción de inconstitucionalidad es su consecuencia y corren igual suerte en el proceso único en que se sustancian. No se crea un nuevo

34 SCBA, 1976, DJBA, 110-57.

35 SCBA, 17-6-97, JA, 1998-I-284; Salgado - Verdaguer, op. cit., p. 431.

36 SCBA, 16-5-95, LL, 1996-B-139.

37 SCBA, Ac. y sent. 1967-2-278.

38 SCBA, I, 1160 , setn. 16-9-86; I, 1159, sent. 25-VIII-87. 
tipo de proceso, sino que con relación a una determinada causa se fijan los efectos que ésta habrá de producir. Negar la posibilidad de acumulación de ambas acciones, implicaría acoger un procedimiento simbólico y formalista que satisfaga un esquema formal que el legislador no desea y el jurista repele, ${ }^{39}$ lo que significa en definitiva obturar el acceso a la justicia, donde ha puesto énfasis la Constitución reformada en 1994 (Art. 150). ${ }^{40}$

Por lo tanto, si bien la finalidad de la demanda originaria de inconstitucionalidad es predominantemente preventiva, en ciertos casos, adquiere carácter reparador, siendo posible, excepcionalmente, acumular a la acción declarativa de inconstitucionalidad otra de condena, así se ha declarado que es admisible la acumulación de una pretensión de condena contra el Estado ${ }^{41}$ o la de anulación del acto lesivo. ${ }^{42}$

\subsubsection{Medidas cautelares}

Puede el actor, al igual que en cualquier otro proceso, solicitar la medida que considere conveniente en salvaguarda de su derecho.

Cuando es verosímil el derecho, previa caución, procede la suspensión cautelar de los efectos de la norma impugnada, en caso de que el inmediato cumplimiento importe innovar en la cosa litigiosa con evidente perjuicio para el actor. ${ }^{43}$

En el orden nacional, la Corte Suprema de Justicia de la Nación ha decidido que la sola circunstancia de tratarse de una acción declarativa no excluye la procedencia de medidas precautorias. En efecto, éstas tienen por finalidad evitar el riesgo de que, durante el transcurso del proceso el pronunciamiento que pudiera reconocer o actuar el derecho, pierda virtualidad. $Y$ ese riesgo puede existir no sólo en el supuesto de las acciones de condena sino también en las declarativas de certeza, en la medida en que se afecte de cualquier manera aquél cuyo reconocimiento se persigue. ${ }^{44}$ Morello, refiriéndose al fallo, expone que

39 SCBA, I, 1329, sent. 10-12-92.

40 Voto del Dr. Hitters; I, 1616, sent. 8-9-98; I, 1541, sent. 29-12-98.

41 SCBA, I 1 165, 22-IV-86; Morelo, Sosa, Berinzonce, Tessone, op. cit., p. 527.

42 Ver este trabajo, punto 2.2 .

43 SCBA, B 49.158, 22-III-88.

44 CS, noviembre 13-1990; “Mendoza, Provincia de c. Compañía Argentina de Teléfonos S.A. y otro s/ Acción declarativa de certeza", ED - 141-697. 
la Corte con flexibilidad y como ha terminado por consagrarse de modo universal en el panorama actual con que operan las medidas cautelares, y aún en el proceso urgente, reconoce que la lograda y funcional norma del Art. $232^{\circ}$ del CPC, faculta al juez a que, adecuándose a las peculiaridades y exigencias diferenciadas que el caso concreto demanda, lleve a cabo con libertad, la opción a favor de la medida más idónea, aunque ella sea distinta de las que la ley tipifica; centrando su respuesta en una interpretación sistemática que involucra por asimilación al Art. $326^{\circ}$, precepto que en sus previsiones contempla matices o exteriorizaciones fronterizas, escabullidas en el proceso cautelar. Empero lo más trascendente y a nuestro parecer adecuado y compatible con sus alcances, que han de acordarse dentro del marco de la acción meramente declarativa que consagra el Art. $322^{\circ}$ de la ley procesal es lo que concierne a las medidas cautelares. En efecto, como se ha postulado en un estudio muy logrado de la problemática global de la referida acción mera (nada más o automáticamente) declarativa, y en torno básicamente de la prohibición de innovar, el que esta última pueda acceder a la pretensión mera declarativa "no debe reputarse extraño ya que, de lo contrario, no tendría sentido ésta última en su faz de prevención si dejara expedita la salida para que el daño o la lesión que tiende a evitar se consumara. ${ }^{45}$

La Suprema Corte de la Provincia de Buenos Aires admite excepcionalmente la procedencia de la medida cautelar de no innovar en la acción de inconstitucionalidad, en los casos en que el inmediato cumplimiento de la norma impugnada importa innovar la cosa litigiosa con evidente perjuicio para el derecho invocado por los actores y porque ello importa una solución anticipada del pleito. ${ }^{46}$

Por regla general este Tribunal ha denegado el pedido de suspensión de los efectos de una ley, ordenanza, decreto o reglamento impugnados mediante la demanda de inconstitucionalidad mientras no se produzca una declaración judicial que establezca lo contrario y por reputar también que si se hiciera lugar, sin más, al requerimiento existiría siempre la posibilidad de desvirtuar sus efectos inmediatos por el mero ejercicio de una acción de inconstitucionalidad. ${ }^{47}$ 
Las medidas cautelares deben examinarse con mayor rigor cuando lo que se procura a través de ellas es la suspensión de los efectos de una ley, decreto, ordenanza o reglamento, puesto que tales actos deben presumirse constitucionales mientras no se produzca una declaración judicial que establezca lo contrario (en el presente caso, la actora no acredito ni la gravedad ni la irreparabilidad del perjuicio que pudiera ocasionarle el cumplimiento de la obligación tributaria, requisitos, éstos indispensable para justificar la procedencia de la medida). ${ }^{48}$

No corresponde hacer lugar a la medida cautelar solicitada si ya se ha consumado el agravio que con el remedio precautorio se procuraba evitar. ${ }^{49}$

Se admite la procedencia del remedio precautorio de suspensión de los efectos de una ley, ordenanza, decreto o reglamento impugnados mediante la demanda de inconstitucionalidad teniendo en consideración la previsibilidad de que diversos actos se tornasen inválidos, por encontrarse apoyados en una norma carente de sustento constitucional, si se juzgase procedente la demanda. ${ }^{50}$

Los presupuestos de admisibilidad de las medidas precautorias deben examinarse con mayor rigor si lo que se procura a través de ellas es la suspensión de los efectos de una ley, pues ésta debe presumirse constitucional mientras no se produzca una declaración judicial que establezca lo contrario, y por reputar también que si se hiciera lugar, sin más, al requerimiento, existiría siempre la posibilidad de desvirtuar sus efectos inmediatos por el mero ejercicio de una acción de inconstitucionalidad. ${ }^{5 !}$

Corresponde no hacer lugar a la prohibición de innovar, dado el carácter excepcional con que se otorgan los remedios precautorios en la acción de inconstitucionalidad si en autos no aparece suficientemente acreditada la verosimilitud del derecho invocado. ${ }^{52}$

No se configura el peligro en la demora requerido por el Art. $230^{\circ}$ del CPCC si no se argumenta de qué modo la modificación de la situa-

48 SCBA, I 1510 I 28-65-91, JUBA 80858.

49 SCBA, I 1432 I 1 1-7-91, “Sergio Sánchez s/ inconstitucionalidad Dec. 175-80»JUBA B81117.

50 SCBA, I 1584 I 4-5-93, JUBA B82640.

51 SCBA, I 1904 I 10-6-97. JUBA B85933.

52 SCBA, I 1713 I 27-6-95. JUBA B84020. 
ción del actor puede llegar a «influir en la sentencia» o convertir «su ejecución en ineficaz o imposible». ${ }^{53}$

No se justifica la tutela cautelar anticipada si la actora no explica los motivos que la llevan a postergar la presentación de la demanda de inconstitucionalidad..$^{54}$

\subsection{Plazo para demandar}

El Art. $684^{\circ}$ del CPCC establece que «la demanda se interpondrá ante la Suprema Corte de Justicia dentro del plazo de treinta días, computados desde que el precepto impugnado afecta concretamente los derechos patrimoniales del actor. Después de vencido ese plazo se considerará extinguida la competencia originaria de la Suprema Corte, sin perjuicio de la facultad del interesado para ocurrir a la jurisdicción ordinaria en defensa de los derechos patrimoniales que estime afectados".

El plazo de caducidad previsto en el Art. $684^{\circ} \mathrm{CPCC}$ comienza a correr desde la aplicación de la disposición cuestionada, ya que en ese momento se concreta la afectación específica a la que la norma se refiere. ${ }^{55}$

Tratándose de normas de carácter general, el plazo corre desde la aplicación de la disposición que produce agrario patrimonial, ${ }^{56}$ sin perjuicio de la facultad de accionar por inconstitucionalidad desde el instante mismo en que la ley rige, ${ }^{57}$ por ejemplo en materia de impuestos, desde que el interesado conoció la liquidación impositiva. ${ }^{58} \mathrm{O}$ desde la fecha en la cual la municipalidad anoticia al contribuyente del aumento dispuesto en el tributo y de la imputación de la cantidad girada al pago parcial del mismo, si al efectuarse éste, aquél desconocía el nuevo monto del gravamen..$^{59} \mathrm{O}$ desde que la interesada quedó notificada de la decisión de la autoridad municipal denegatoria de su solicitud de exención impositiva, pues ese es el momento en que la actuación de

53 SCBA, I 2144 I 26-5-98. JUBA B86982.

54 SCBA, I 2144 I 26-5-98. JUBA B86983.

55 SCBA, marzo 5 de 1996, "Clínica Cosme Argerich Neuropsiquiátrico SA s. Inconstitucionalidad». Carpetas DP, 1486.

56 SCBA, I 1514, 23-4-91.

57 SCBA, Ac. y Sent. 1971-II-701.

58 SCBA, Ac. y Sent. 1970-II-83.

59 SCBA, Ac. y Sent., 1968, p. 1093. 
las normas impugnadas han afectado concretamente sus derechos. ${ }^{60} \mathrm{El}$ tema de la publicación tardía de la norma impugnada -esto es-, luego de su aplicación al accionante-, carece de relevancia como fundamento de la pretensión declarativa de inconstitucionalidad, si dicha circunstancia y, por ende, el agravio que con sustento en ella se plantea, perdió actualidad pocos días después no afectó el ejercicio de la defensa del interesado, pues el contenido de su demanda demuestra que tenía entonces un pleno conocimiento de la norma. ${ }^{61}$

Por otra parte el Art. $685^{\circ}$ del CPCC prescribe que «no regirá dicho plazo, cuando se trate de leyes, decretos, ordenanzas o reglamentos, de carácter institucional o que afecten derechos de la personalidad no patrimoniales. Tampoco regirá cualquiera sea la naturaleza de los preceptos impugnados, cuando éstos no hayan sido aún aplicados al demandante y la acción se ejercite con finalidad preventiva.»

El plazo de caducidad no rige respecto de las cuestiones institucionales, las que afecten derechos extramatrimoniales y cuando los preceptos impugnados aún no han sido aplicados al actor, ${ }^{62}$ por extensión, tampoco cuando se trata de normas que regulan los beneficios jubilatorios. ${ }^{63}$

La cuestión vinculada de modo directo e inmediato a los derechos de propiedad y libertad de trabajo, industria o comercio, aparece con nítidos caracteres institucionales y el contenido de la causa petendi provisto de una densidad constitucional tal, que destaca la prioridad que cobra frente a todo otro de diversa índole y, por ende, aunque no esté ausente el interés y eventual agravio patrimonial, como ello es consecuencia mediata de las ordenanzas impugnadas, se está ante el supuesto que contempla el artículo $685^{\circ}$ del ordenamiento procesal, que descarta la aplicación de plazo alguno para reclamar la declaración de inconstitucionalidad, ya que la jurisdicción originaria de la Suprema Corte se encuentra abierta en todo momento, cuando se afectan garantías individuales que la constitución provinciana enuncia y ampara. ${ }^{64}$ Consecuentemente, impugnada una ordenanza como violatoria de una

60 SCBA, Ac. y Sent., 1973, p. 1150.

61 SCBA, I 1335, S 29-9-94 “Club Atlético Brown c/ Provincia de Buenos Aires s/ Inconstitucionalidad decreto 690-88 JUBA B 83503.

62 SCBA, Ac. y Sent. 1973-II-11 142.

63 SCBA, I 1287, 28-III-89.

64 SCBA, Ac. y Sent. 1967, v. II, p. 205; 1969, p. 333; La Ley, v. 136, p. 356. 
libertad individual consagrada por la Constitución provincial, la demanda de inconstitucionalidad contra aquélla se ha interpuesto debidamente, aunque se hubiera excedido el plazo legal de un mes. ${ }^{65}$

En cuanto a los derechos extramatrimoniales la Suprema Corte ha resuelto, por ejemplo, que la acción que persigue la inconstitucionalidad de una ley que reglamenta la profesión de martillero y corredor público, regulando derechos de la personalidad que desbordan su contenido meramente patrimonial, no se encuentra sometida al plazo de interposición que establece el artículo $684^{\circ}$ del código procesal. ${ }^{66}$

\subsection{La demanda. Traslado}

El Art. $686^{\circ}$ establece que: «el Presidente del Tribunal dará traslado de la demanda, por quince días:

1. Al asesor del gobierno, cuando el acto haya sido dictado por los poderes legislativo o ejecutivo.

2. A los representantes legales de las municipalidades, o a los funcionarios que ejerzan la titularidad de los organismos involucrados, cuando los preceptos emanaren de dichas entidades".

El examen de admisibilidad de la demanda lo realiza la SCBA de oficio, in limine litis; de lo contrario, lo efectúa al dictar sentencia. ${ }^{67}$

Se confiere traslado de la demanda al asesor de gobierno cuando el acto impugnado ha sido dictado por los poderes legislativo o ejecutivo. De encontrarse involucrado algún municipio, se notificará al representante legal de la respectiva municipalidad. ${ }^{68}$

Si la demanda de inconstitucionalidad ataca un decreto del Poder Ejecutivo de la Provincia que ha convalidado un decreto-ordenanza municipal, el asesor general de gobierno es parte obligada en la sustanciación del proceso, por lo que corresponde declarar la nulidad de lo actuado si se ha omitido dar traslado de la demanda a ese funcionario y subsanar tal omisión. ${ }^{69}$

65 SCBA, Ac. y Sent., 1961, v. I, p. 61.

66 SCBA, Ac. y Sent., 1972, v. II, p. 20.

67 SCBA, I 1 p. 465, I-IV-93.

68 Fenochietto, "Código Procesal Civil y Comercial de la Provincia de Buenos Aires», Ed. La Rocca, año 1996, p. 650.

69 SCBA, Ac. y Sent., 1974, v. I, p. 261. 
El allanamiento del asesor de gobierno no obliga a la SCBA a declarar la inconstitucionalidad. ${ }^{70}$

Cabe la citación coactiva o intervención voluntaria de un tercero órgano público no estatal-cuando surge prima facie que el resultado del pleito puede afectar intereses propios de aquel. ${ }^{71}$

\subsection{Medidas probatorias}

El Art. $687^{\circ}$ prescribe que «contestado el traslado o vencido el plazo, el Presidente ordenará las medidas probatorias que considere convenientes fijando el término para su diligenciamiento. Concluida la causa para definitiva, se oirá al Procurador General y se dictará la providencia de autos".

El actor, se tiene pronunciado, debe cumplir con la carga de postulación y prueba que le incumbe, no sólo por su situación procesal, sino también por la presunción de constitucionalidad de que gozan las leyes y los límites dentro de los cuales corresponde a los jueces realizar el control de constitucionalidad, puesto que no pueden de oficio, por su propia iniciativa, hacerlo en el caso de los actos legislativos o administrativos. ${ }^{72}$

\subsection{Contenido de la decisión}

El Art. $688^{\circ}$ estatuye «si la Suprema Corte estimase que la ley, decreto, ordenanza o reglamento cuestionados, son contrarios a la cláusula o cláusulas de la Constitución que se citaron, deberá hacer la correspondiente declaración sobre los puntos discutidos. Si por el contrario, no halla infracción constitucional, desechará la demanda".

Se trata de una sentencia declarativa. ${ }^{73}$ Rige el principio de congruencia. ${ }^{74}$ No caben pronunciamientos abstractos, como ocurre cuando la norma reputada inconstitucional no se encuentra vigente al tiempo

70 SCBA, I 1285, 27-VI-89.

71 SCBA, I 1548, 2-III-93.

72 SCBA, 2-6-81, I-1084, Doctrina, junio 1981, No 35. Fenocchietto, op.cit., p. 651.

73 SCBA, Ac. y Sent. 1970-II-221.

74 SCBA, I $1197,14-$ III-89. 
de la sentencia. ${ }^{75} \mathrm{El}$ allanamiento del Asesor General de Gobierno no exime de las costas. ${ }^{76}$

La función meramente declarativa de la sentencia se desprende expresamente del texto del artículo citado, pues la Corte se limitará a declarar, simplemente la inconstitucionalidad de la ley atacada, o de contrario, si no encuentra infracción constitucional, desechará la demanda.

\section{El control de constitucionalidad en el Código contencioso administrativo de la Provincia de Buenos Aires}

La Constitución de la Provincia de Buenos Aires en el Art. $166^{\circ}$ in fine, establece que «los casos originados por la actuación u omisión de la Provincia, los municipios, los entes descentralizados y otras personas, en el ejercicio de funciones administrativas, serán juzgados por tribunales competentes en lo contencioso administrativo, de acuerdo a los procedimientos que determine la ley, la que establecerá en los supuestos en que resulte obligatorio agotar la vía administrativa."

En el año 1997 se sancionó el Código Contencioso Administrativo. ${ }^{77}$

A partir de la sanción de dicho Código existe una vía procesal alternativa que posibilita brindar una adecuada tutela jurisdiccional a las pretensiones de los justiciables con relación a los actos aplicativos de normas reputadas inconstitucionales, permitiendo, por ende que la acción declarativa de inconstitucionalidad se canalice a su finalidad específica, esto es, el cuestionamiento de mandatos generales y abstractos que colisionan con la Carta Magna provincial. ${ }^{78}$

El fuero contencioso administrativo comenzó su vigencia en forma conjunta con el Código Procesal de la materia a partir del $1^{\circ}$ de octubre de 1998. Hasta tanto comience sus funciones, la Suprema Corte de Justicia decidirá, en única instancia y juicio pleno, todas las causas correspondientes al referido fuero que se hubieren iniciado hasta su finalización. ${ }^{79}$ 
La demanda de inconstitucionalidad (Art. $683^{\circ}$ a $688^{\circ} \mathrm{CPCC}$ ) sólo tiene aunamiento cuando el precepto infringe cláusulas constitucionales, mas no cuando transgrede normas de jerarquía inferior a la Constitución. ${ }^{80}$

Si se controvierte la constitucionalidad de un acto de alcance general reglamento, decreto u ordenanza- por colisionar con la ley a la que se subordina, tal vicio debe plantearse como defensa en el carril procesal administrativo, en el marco de la pretensión de anulación de actos de alcance general (arts. $3^{\circ}, 12^{\circ}$ inc. $1,50^{\circ}$ inc. $5,67^{\circ}$ a $70^{\circ}$ del CCA).

La acción originaria no es la vía idónea para cuestionar la validez de resoluciones administrativas que decidan casos particulares o de alcance singular, pues tales resoluciones no revisten categoría de leyes, ordenanza o reglamentos. ${ }^{81}$

Cuando se sostiene que un acto administrativo de alcance particular colisiona directamente con alguna cláusula de la Constitución Nacional o Provincial, el planteo de inconstitucionalidad debe formularse en el proceso administrativo, en el marco de la pretensión de anulación, ya sea por vía ordinaria o sumaria de ilegitimidad (arts. $2^{\circ}$, inc. 1 , $3^{\circ}, 12^{\circ}$, inc. $1,50^{\circ}$ inc. $5,67^{\circ}$ a $75^{\circ} \mathrm{CCA}$ ).

\section{Conclusiones}

1. El control de constitucionalidad del derecho local se realiza: a) por medio del sistema difuso y b) a través de las llamadas acciones declarativas de inconstitucionalidad, que están concentradas en la competencia originaria de las cortes supremas locales.

2. La acción declarativa de inconstitucionalidad (Art. $161^{\circ}$ inc. 1 CPBA y arts. $683^{\circ}$ a $688^{\circ} \mathrm{CPCC}$ ) cumple una función eminentemente preventiva, pero también puede ser anulatoria si se cuestiona paralelamente a la norma general; la «aplicación» que se hizo de ella, cuando el perjuicio ya se ha producido.

3. Dicha acción procede por infracciones a la Constitución de la Provincia, en la medida que la norma cuestionada se encuentre vigen-

80 SCBA, causa I 1.306, sent. 28-V-91.

81 SCBA, causas I 1471, int. 20-1 1-91; I 1632, sent. 28-9-93; I. 1308, sent. 28-6-94 entre otras. 
te o subsistan sus efectos, y por esa vía únicamente son impugnables las normas que, con independencia de su denominación (ley, decreto, ordenanza, reglamento), constituyen mandatos generales, abstractos e impersonales dirigidos a la comunidad.

4. Para promover la demanda de inconstitucionalidad es necesario acreditar la calidad de parte interesada. El interés legítimo depende de la concurrencia de actos inequívocos que revelen que el precepto impugnado ha sido y será indudablemente aplicado al actor.

5. Excepcionalmente se ha resuelto que es admisible la acumulación de la acción de condena a la de inconstitucionalidad.

6. La Suprema Corte de la Provincia de Buenos Aires admite excepcionalmente la procedencia de las medidas cautelares. En este caso, los presupuestos de admisibilidad de dichas medidas deben examinarse con mayor rigor, pues la constitucionalidad de las normas se presume mientras no se produzca una declaración judicial que establezca lo contrario.

7. El plazo de caducidad de treinta días (Art. 6840 CPCC) comienza a correr desde la aplicación de la disposición cuestionada que produce agravio patrimonial y no rige respecto de las cuestiones institucionales ni de las que afecten derechos extramatrimoniales.

8. Si la Suprema Corte estima que la norma cuestionada es contraria a la Constitución Provincial deberá así declararlo, si por el contrario no halla infracción constitucional, desechará la demanda.

9. A partir de la sanción del Código Contencioso administrativo de la Provincia de Buenos Aires existe una vía procesal alternativa que posibilita brindar una adecuada tutela jurisdiccional a las pretensiones de los justiciables con relación a los actos aplicativos de normas reputadas inconstitucionales, permitiendo, por ende que la acción declarativa de inconstitucionalidad se direccione a su finalidad específica, esto es el cuestionamiento de mandatos generales y abstractos que colisionan con la Carta Magna Provincial. 